\title{
Old Is the New New: The Rhetoric of Anchoring Innovation
}

\author{
Ineke Sluiter
}

\begin{abstract}
In life, language, and argument, we need to feel at home. "Anchoring" connects whatever seems "new" to what is considered familiar. This paper studies the argumentative use of "anchoring" in the wider context of its role in language use. "Anchoring" provides a unifying perspective in analyzing linguistic and rhetorical elements identified by different schools of thought (Sect. 2). Several features of language, elsewhere studied in the context of "discourse linguistics", direct the addressee on how to anchor new information to the common ground. Categorizing, labeling and naming (topics from philosophy and psychology) can be considered anchoring functions. And formal linguistic iconicity anchors linguistic representations in evolutionarily older senso-motor systems. Section 3 discusses the anchoring effects of some specific discourse types: genealogy, mythology, aetiology, and etymology. All of these frequently take the form of narrative and are used in affective, "engaged" argumentation. Finally, the rhetorical and argumentative implications of the terminology of "new" and "old" itself are discussed, and one specific "anchoring trope" is analyzed, which sets up an anchor as a reference point for something new: the phrase " $\mathrm{X}$ is the new $\mathrm{Y}$ " (Sect. 4).
\end{abstract}

Keywords Anchoring - Innovation $\cdot \mathrm{X}$ is the new $\mathrm{Y} \cdot$ Affective argument Association

\section{Introduction}

Human experience is an onslaught of phenomena that are either presented to us as new or strike us as such. Whenever this happens, a cognitive process or activity of integration may be activated (or not: we may also fail to observe things, fail to comprehend or accept them, or even actively ignore and block them).

We live in an era in which innovation is a buzz-word, although it is mostly (and wrongly) reserved for specific developments in technology, the sciences, and

\author{
I. Sluiter $(\varangle)$ \\ Centre for the Arts in Society, Leiden University, Leiden, The Netherlands \\ e-mail: i.sluiter@hum.leidenuniv.nl
}


medicine. However, innovations may affect every domain of life, and the social sciences and the humanities have much to offer for a more general understanding of how people process "the new" and how they cope with it. In particular, it is crucial to understand that without attention to "the human factor", no invention will turn into an (accepted) innovation. A Dutch research team of classicists has used the term "anchoring" for such a forging of a connection between "the new" and what is already familiar. A central hypothesis is the following:

Innovations may become acceptable, understandable, and desirable when relevant social groups can effectively integrate and accommodate them in their conceptual categories, values, beliefs and ambitions. This is the case when they can connect what is perceived as new to what they consider familiar, known, already accepted, when, that is, innovations are "anchored". (Sluiter 2017: 23) ${ }^{1}$

"Anchoring" is a basic condition for successful linguistic exchanges, an instrument of argumentation, and one of the goals of persuasive rhetoric. This paper studies the argumentative use of "anchoring" against the wider backdrop of its role in language use. The concept of "anchoring" will be used to provide a unifying perspective on linguistic and rhetorical elements and concepts from different levels of analysis and different schools of linguistic thought, without denying or eliding relevant distinctions.

\section{The Linguistics of Anchoring Innovation}

On a very fundamental level and without needing the lexeme "new" as a signpost, linguistic communication itself is a prime example of "anchoring innovation", or maybe better: "anchoring the new". In any felicitous act of communication, there is a constant mutual assessment of the amount of relevant knowledge available to the different partners in communication, and a gradual addition of new information. Crucially, this new information must constantly be anchored in the "common ground", defined by Clark as: "the sum of [two people's] mutual, common, or joint knowledge, beliefs, and suppositions" (Clark 1996: 93). ${ }^{2}$ This common ground may contain both items of culturally shared information, and individually or personally shared information (Clark 1996).

As Allan, van Gils, and Kroon have demonstrated from a pragmatic or discourse linguistic perspective, different linguistic devices can be fruitfully regarded as tools for common ground management, in that they actively "anchor" new information

\footnotetext{
${ }^{1}$ The research program is coordinated by OIKOS, the Dutch National Research School in Classical Studies. See the website: https://www.ru.nl/oikos/anchoring-innovation/. The program is supported by a 2017 so-called "Gravitation Grant" from the Dutch Ministry of Education.

${ }^{2}$ First discussion in Clark and Brennan (1991); Stalnaker (2002); see Camp (2018) for discourse strategies of plausible deniability that never fully adds information to the common ground; for applications in Classics, see e.g. Huitink (2009), here especially p. 24, on presupposition; in the anchoring innovation program, see Allan and van Gils (2015), Kroon (2015, 2019).
} 
to the common ground. Examples are the use of the so-called historical present tense (praesens historicum) (Kroon 2015), the use of anaphoric deictic pronouns (Kroon 2017) and the use of discourse particles and negation, understood as "the speaker's instruction to the addressee specifying in which way new information is to be cognitively anchored to the already established common ground" (Allan and van Gils 2015; van Gils 2016; Allan 2017). ${ }^{3}$ The Latin particle enim, for instance, can be used to introduce an explanation ("for") of what has just been said before, while also suggesting that this information is already shared between speaker and addressee and thus part of the common ground ("for, as we both know").

If tenses, discourse particles and negations can serve as linguistic devices to anchor information to the common ground, "categorization" and "labelling" are conceptual anchoring activities that particularly affect our use of nouns and sometimes verbs. In this context, the term "anchoring" was used in an influential paper by Bauer and Gaskell (1999). ${ }^{4}$ They restrict their use of the term "anchoring" to the "naming and classifying of novel encounters, ideas, things or persons" (Bauer and Gaskell 1999: 172). This is certainly an important and basic form of integrating the new into existing conceptual structures. A helpful first step in cognitively processing the new and connecting it to what is already familiar is to find an answer to the question "what is this?".

To give an example from classical literature: this whole idea was dramatized to great comic effect by Sophocles in his Satyr play The Searchers (Gr. Ichneutai). A chorus of satyrs is trying to find a herd of stolen cattle, which in the end will turn out to have been taken by the baby god Hermes. But they are disturbed and scared by an underground sound they have never heard before. As it turns out, baby Hermes had just managed to invent the lyre, by fastening strings into the shell of a tortoise, and the sound is that of its music. Of course, the lyre is a cultural object well-known to the audience, who here witness what happens when the chorus tries to figure out for the first time, in a dialogue with a nymph, "what this is". In effect, they witness the anchoring of an invention in the categories available to the satyrs. ${ }^{5}$ When they have more or less figured out what kind of (dead) animal is at the source of the sound, they finally come around to the question "What is the name you give it?" (verse 311), and the nymph replies: "the boy (Hermes) calls the animal a 'tortoise', and the thing that makes the sound a "lyre"". Now they know what the instrument looks like, what it

\footnotetext{
${ }^{3}$ For an example of this anchoring use of negation, see Sect. 4 (example c). Its technical effect can be compared to the argumentative concept of "dissociation", in the terminology of Perelman and Olbrechts-Tyteca (1969: 190-191) and van Eemeren (2019: 157). Dissociation is defined as "techniques of separation which have the purpose of dissociating, separating, disuniting elements which are regarded as forming a whole or at least a unified group within some system of thought" (Perelman and Olbrechts-Tyteca 1969: 190). Van Eemeren uses it specifically for the (negative) clarification of a vital term. "Dissociation" is the opposite of "association", which refers to the bringing together of separate elements and establishing a unity among them.

${ }^{4}$ Who in turn refer to Moscovici (1976).

${ }^{5}$ I thank Efstathia Athanasopoulou for bringing this example to my attention through her paper "Anchoring cultural objects in the ancient Greek imagination" during the conference "How to Do the Psychology of the Ancient World". Leiden 13-15 December 2018.
} 
Fig. 1 Two enigmatic objects

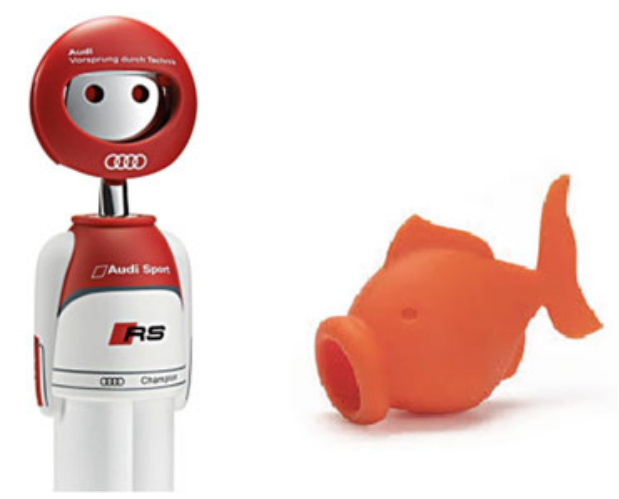

does, and what it is called. We are on the way to having the lyre be part of Greek culture.

Sophocles was imagining the process of categorization necessary to accommodate a new invention in the lexicon. A historical example of such anchoring through categorization is studied as part of "lexical acculturation theory" by Goldwasser (2017). She analyses the process through which the arrival of the horse is marked in Egyptian, Sumerian and Nahuati. This is done partly through adopting loan words, but also through referential extension or semantic insertion into a known category: in Mesopotamian the horse is called a "donkey of the mountain". 6

There are many more banal examples derived from the propensity of the design industry to invent such cute packaging for their products that one is made to ask "what is this?"/"what is this for", in order to anchor the new into the familiar. People who acquire such gadgets enjoy a privileged position vis-à-vis newcomers (such as visitors): from a position of superior knowledge, they can enlighten, if they so choose, the outsiders: "Guess what this is?", "Guess what I've got!". The object is anchored for one partner in the exchange and not yet for the other, and the appeal to belong to the "in-group" is exploited as an implicit argument by marketeers. Figure 1 offers two examples:

Well might one be puzzled by these two objects. The object to the left resembles a Formula-1 racer, dressed in protective gear and helmet, with the Audi logo visible on the helmet. The object to the right is an orange fish made of silicone, with an open mouth. One cannot make much more of it. But with some helpful instructions, we can categorize and label each of these novel cultural objects. The AudiStore website reveals that the little racer is in fact a corkscrew, designed on the basis of the legendary cork screw "Alessandro" by designer Alessandro Mendini-a.k.a. Alessi. When the red helmet is taken off, the actual corkscrew is revealed. ${ }^{7}$ For the orange fish, it is best to refer to Fig. 2, although here, too, the crucial thing we need to know is the name: "yolkfish egg separator"

\footnotetext{
${ }^{6}$ Goldwasser (2017) also refers to Eco (2000: 127-130) for different strategies to anchor a new cultural item.

${ }^{7}$ https://store.audi.co.uk/audi-sport-corkscrew19991.html. Accessed Jan. 2019.

${ }^{8}$ https://peleg-design.com/products/yolkfish. Accessed Jan. 2019.
} 
Fig. 2 How to use the yolkfish egg separator

Fig. 3 "Beep-egg"
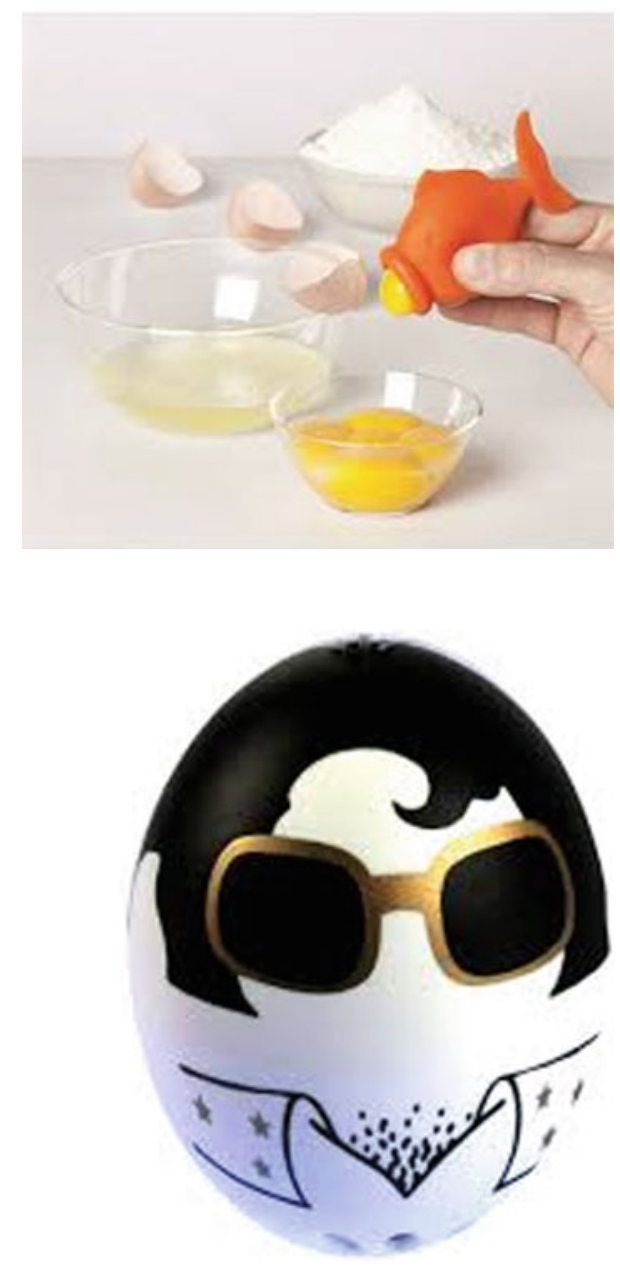

Just having the labels/categories of "corkscrew" and "egg separator" makes all the difference for knowing what we are supposed to do with these objects. Similarly, it is hardly obvious that if you put the egg depicted in Fig. $3^{9}$ in with the eggs you are trying to boil, it will start singing (as it will in fact do) "Killing me softly" once the egg is a perfectly soft-boiled. Not even the name "beep-egg" will help you grasp its purpose (as an immersive egg timer) on its own, although once you know what the implement is for, it is a helpful moniker. "Beep-egg" is the kind of invention that tries to create its own need-you didn't know you wanted it before it existed.

${ }^{9}$ http://sleepychef.com/the-king-beep-egg-timer-piep-ei-elvis-presley-edition/. Accessed Jan 2019 
Finally, as a transition to discussing higher-level (rhetorical, discursive, and argumentative) forms of anchoring, there is the linguistic anchoring provided by iconicity: in iconic language the formal aspects of an utterance "resemble" their conceptual content (Nijk 2018). ${ }^{10}$ Sound effects, rhythmic patterns or cola length, for instance, can all be used to promote ease of processing of the conceptual content. The principle of quantity suggests that morphologically heavier forms will convey "extra" meaning. An example is the formation of comparatives, as in "great - greater". Such aspects of form, it is argued by Nijk (2018) who first connected the topic with "anchoring", are cognitively processed by systems of perception and motor control that are evolutionarily older than those of reasoning. Iconicity appeals to the older systems and thereby anchors our capacities for rational understanding. As with the pragmatic and discourse-linguistic studies mentioned above, this effect of linguistic iconicity is best explained within the framework of cognitive linguistics as promoting ease of processing, as an anchor for understanding.

\section{Genealogy, Mythology, Aetiology, and Etymology as Discursive Anchoring Practices}

Whenever something that presents itself as new is being anchored for the relevant social groups in something familiar, this is often brought about through analogy, considered the most basic human cognitive strategy by Hofstadter and Sander (2013). The familiar analogue that one invokes may be a case of "horizontal anchoring", in which case the new in one domain is related to the familiar in another, contemporary, one. Or one may engage in "vertical anchoring", when a new object, idea, practice or technique is related to something familiar from the past. One example of horizontal anchoring, fitting Bauer and Gaskell's (1999) emphasis on categorization and labeling, was the "donkey of the mountain", to indicate a "horse". Another example is the explanation of a "drone" as "a flying computer with a camera or sensor attached". A drone is a specific kind of the presumably better-known computer. ${ }^{11}$ Similarly, there must be several Business Books out there that exploit a parallelism between business and sports. ${ }^{12}$ Vertical anchoring is exemplified by the slogan of the current President of the United States: MAGA. "Make America Great Again" appeals to feelings of nostalgia for an ill-defined but happy past greatness, which the new regime claims to bring back. Anchoring is here directly connected with persuasion and argumentation: it can win elections. ${ }^{13}$

\footnotetext{
${ }^{10}$ For the related concept of "depiction", see Clark (2016).

${ }^{11}$ https://www.dronezon.com/learn-about-drones-quadcopters/what-is-drone-technology-or-howdoes-drone-technology-work/. Emphasis added. Accessed Jan. 2019.

${ }^{12}$ As just one example: Perry and Jamison (1997).

${ }^{13}$ Again, Perelman and Olbrechts-Tyteca's notion of "association" is relevant (1969: 190-191); van Eemeren 2019: 156-157; 159 (on symptomatic and comparison argumentation).
} 

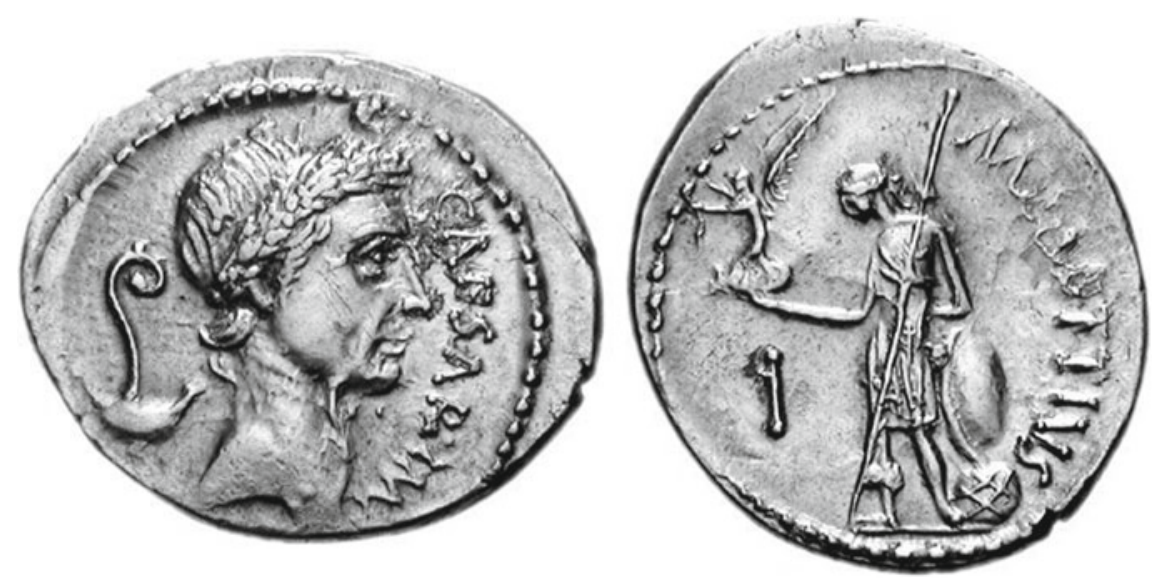

Fig. 4 Coin from the time of Julius Caesar, showing a bust of Caesar on one side and a depiction of Venus holding Victory on the other. Wikimedia commons

There are various identifiable types of discursive practices or discourse types ("-logies") that specifically contribute to "anchoring" the (new) present either by emphasizing its unbroken continuity with the past, or by explaining a certain aspect of the status quo on the basis of the past. These practices, which frequently and heavily rely on cultural memory, are genealogy, mythology, and aetiology. Each of these is affectively charged and hence contributes to an "engaged" style of argumentation (van Eemeren 2019: 166), which is a style that shows an arguer's close involvement. In addition, there is the ancient and medieval practice of etymology (to be carefully distinguished from the academic discipline of etymology as originating in the 19th century), which anchors an understanding of the present in an important element of the common ground: language itself. All these four types of discourse can take the form of an explanatory narrative, and they are frequently used as argumentative devices.

Genealogy determines the place in the world of the latest link in a chain of direct descent by connecting it to some meaningful point of origin in the past. In classical antiquity, such a meaningful point of origin might be a god (or goddess) or a hero: this is the (argumentatively constructed) anchor. The Julian dynasty, for instance, particularly Julius Caesar and his (adoptive) son Octavian, better known as the first emperor Augustus, traced their lineage through the Trojan hero Aeneas to the goddess Venus (Aphrodite). Aeneas, who was to lay the groundwork for the foundation of Rome, was the son of the goddess Aphrodite and a human father, Anchises. The epic poem Aeneid thus provided a genealogical anchor for Augustus, one that underpinned his position of authority. ${ }^{14}$ Obviously genealogy and mythology go hand in hand here. Julius Caesar would call attention to his descent by featuring the goddess Venus on his promotional coinage (Fig. 4). And Augustus would do the same, emphasizing in

\footnotetext{
${ }^{14}$ The more critical tendencies of the Aeneid cannot be discussed here.
} 
the legend on the coin that he was divi filius, the son of the deified Julius.

In the New Testament, there are two genealogies of Jesus, one in the Gospel of Matthew, the other in the Gospel of Luke. Matthew (1.1-17) puts his version right at the beginning of his text. He states that Jesus is a "son" (i.e. descendant) of David, son of Abraham, and this serves two implicit arguments: in this way he secures his lineage as a King (by anchoring to David) and as a part of Israel (by anchoring to Abraham). The genealogy in Luke 3:23-38 is set at the juncture where Jesus takes up a more public role. In this passage Jesus' descent is traced to Adam, "son of God" (3:38).

And, si parva licet componere magnis, at the Pieterskerk (Peter's Church) in Leiden, there is a commemorative plaque with the names of the Pilgrim Fathers who set forth from Leiden to the United States. An explanatory sign specifies which Presidents of the United States could trace their descent to the Pilgrims. Among the nine who qualify are both Presidents Bush. Another Pilgrim descendant is President Obama. ${ }^{15}$ For all these Presidents, the symbolically meaningful genealogy stops there, although clearly the Pilgrim Fathers themselves had also descended from someone. But this is how anchoring works. In this case it provides an argument both for the status of these Presidents and for the importance of the role of Leiden in the voyage of the pilgrims.

We have already seen an example of mythology as an anchoring discourse in the Aeneid. Myths provide social groups with a meaningful set of stories that can help explain or even justify the status quo. It is this particular role for the present of the narrators and recipients that defines it as an anchoring practice and explains its argumentative force. Myths identify or construct formative moments in the past, and thus help, among other things, to create a sense of group identity in the present by providing a common frame of reference.

For the ancient Greeks, the story of the Trojan war defined the moment at which they came together as a group, and it came to function as a normative charter myth, by which one might justify certain political or military situations. When in a later war (against the Persians) the Athenians and the Spartans were looking for allies and turned to Sicily, the Sicilian king Gelon announced his willingness to help on condition of becoming the supreme commander. The Spartan ambassador answered first and in his argument pointed out that Agamemnon- the commander of the Greeks in the Trojan War-would basically turn over in his grave if he saw the Spartans hand over military leadership to Gelon and his Sicilians. At this Gelon relented a bit and suggested that the Spartans could command the land army if he himself were made commander of the navy. But now the Athenian envoy protested, with a double appeal to mythological anchors: the Athenians, he argued, were the oldest people and had never been migrants (in other texts this is called "autochthony", the condition of "being sprung from the land itself"). ${ }^{16}$ And, secondly, like the Spartan had done, the Athenian also makes an instant and serious reference to the Iliad. Surely, the Athenians had to remain in the lead, since "Homer, the epic poet, had said that the

\footnotetext{
${ }^{15}$ https://www.mayflower400uk.org/visit/leiden-holland/.

${ }^{16}$ Many sources brought together in Loraux (2006), e.g. pp. 209-217.
} 
man who had come to Troy as the very best at putting an army in order and organizing it, was one of the Athenians". ${ }^{17}$ Mythology could be put to normative use, anchoring an argument in an affectively charged, "engaged" way. In this case, however, it failed to help the Athenians to acquire their coveted ally.

Aetiology is another specific kind of explanatory or justifying discourse. In the study of ancient literature, the term is usually reserved for the explanation, based on past origins, of a specific custom, object, or practice (see Klooster and Wessels forthcoming). Many Greek tragedies feature such an aition, an explanatory narrative. One example is the story of how the murder court of the Areopagus originated. Historically, this had taken place in $462 \mathrm{BCE}$, when the Areopagus, initially a "council of elders", saw its purview radically restricted to that of a court in which cases of intentional homicide (and some other things) were tried. Four years later, the tragedian Aeschylus produced a trilogy (the Oresteia), three coherent tragedies set in the mythical past: the aftermath of the Trojan war. In the last of the three plays, the Eumenides, the central issue was the fate of Orestes, who had murdered his mother in order to take revenge for his father Agamemnon, and who was now being persecuted by the Furies. In order to end the intrafamilial bloodshed, Orestes' case was brought to trial in a court that was organized for the first time for this purpose. The Furies were the accusers, Orestes was defended by the god Apollo. The goddess Athena presided over the court and when the vote was a tie, hers was the casting vote that acquitted Orestes. In the political circumstances of mid-fifth-century-BCE Athens, this story was an overt, but apparently welcome, attempt at anchoring innovation. It showed how ancient feuds could be laid to rest in an orderly way through a court of law, in Athens and with the help of the Athenian city goddess Athena and a jury of Athenian citizens. It anchored their (virtually brand-new!) court in an affectively charged way to the most canonical myths in the Greek playbook and this rhetorical association was a strong argument for its value and legitimacy. The play won first prize.

This is not to say that no other explanatory stories about the Areopagus were available, and in fact this takes us to the fourth type of ancient anchoring discourse, that of etymology (see Sluiter 2015). This discursive practice in no way resembles the systematic study of language change that we have called by the same name since the 19th century: the modern form engages in identifying the conditions and laws that determine how phonemes develop over time through a comparative approach. It determines one single historical development for each word form in question. On the other hand, the practice of ancient etymology creates an explanatory and interpretive semantic relationship, on the basis of often superficial and partial similarities in sound, between the word in question and the "definition" contained and hidden within the word-form itself, if only one knows how to unpack it. Such a definition (the etymology) serves to explain form and meaning (in the present) at the same time. In other words, language itself is seen as part of the culturally shared common ground between speaker and addressee, and one may refer to it in argument, when

\footnotetext{
${ }^{17}$ The story of this debate is found in the Histories by Herodotus (7.157-162); the Spartan refers to Agamemnon at 7.159; the Athenian's answer at 7.161.3; the reference is to Iliad 2.552-554.
} 
attempting to explain or justify the world around us. It is a form of "thinking with language". As argued elsewhere,

(...) ancient etymology is ultimately all about synchrony, even though it invokes a discourse that references the past. It is about the relationship between words and their semantic explanation or definition - it wants to know why anything is called what it is called, the reason for the name, and what motivates the namegiver (Sluiter 2015: 898).

To return to the Areopagus: this word has a transparent meaning as the areios pagos, "the hill of Ares", and this fact itself probably inspired an alternative explanation of how its judiciary function originated: the god Ares was tried there for murdering a son of Poseidon, who had raped one of Ares' daughters. ${ }^{18}$ The name was there first, the later function triggered a new explanation of the name. Such a story may also have had a mnemonic function, creating a mental link between name, mythology, and well-known juridical function. In modern Greece, incidentally, the Areios pagos is the name of the Supreme Civil and Criminal Court of Greece-and it is obviously no longer located on the hill of Ares.

Ancient and medieval etymologies are often accompanied by the language of causality, motivation, explanation, and justification. In the Etymologies by Isidore of Sevilla, for instance, the following is offered as the explanation for the word litterae "letters"

litterae autem dictae quasi legiterae, quod iter legentibus praestent

"litterae [letters] are called as it were leg-iterae, because they show readers (leg-entibus) the way (iter)."

Such etymologies use the formal aspects of language itself as a cognitive support for its meaning. Ancient uses of etymology often serve as a rhetorical argument, using language itself as a locus of inventio, the place where one might find rhetorical ammunition for one's positions. And in fact this sometimes carries over into our own time, as with the frequently found internet wisdom: "Each day is a gift. That's why it's called the present". Ancient etymologists could not have put it better: there is an assertion. And to reinforce the claim contained in it, there is an argument based on a causal ("that's why") explanation based on language itself that hinges on the double use of the word "present", both for "what is now", i.e. "this day", and for a "gift". Each day may be called "the present", so clearly it's a gift. The only thing lacking is the phonetic resemblance between the words that would have clinched the matter in ancient Greek or Roman ears. ${ }^{20}$

Modern examples of this type of etymology are usually classified as "folk etymology", although it should be noted that in Antiquity its argumentative use can be

\footnotetext{
${ }^{18}$ The Parian marble or Parian chronicle dates this event to 1531/0 BCE, see Rotstein (2016) (especially https://chs.harvard.edu/CHS/article/display/6483.2-text-and-translation).

${ }^{19}$ Isid. Etym. I iii 2.

${ }^{20}$ The argumentative form of the example would have been called metalepsis in Antiquity. See Sluiter (1990, 111-117), also for a relationship with etymology "proper" (at note 274). The causal type of argument scheme (as a form of "association") is part of van Eemeren's typology (2019: 159); see above notes 3 and 13 .
} 
found in all kinds of (literary, scholarly) texts. ${ }^{21}$ It is simply a different kind of "language game" than "our" form of academic etymology. A modern example is the re-etymologizing of the word "hamburger", derived from the German city of Hamburg, as a compound from "ham" and "burger", leading to new formations such as "cheese-burger", or "fish-burger". "Look at all these burgers!", said President Trump, when hosting a national college football champion team at the White House on January 14th, 2019. Nothing wrong with that linguistically speaking.

\section{The Terminology of "Old" and "New" and an Anchoring Trope}

The most obvious linguistic aspect of dealing with the old and the new is when those actual lexemes are being used. These words evoke a frame of change and development. It is important to note that "old" and "new" are not only used as descriptive labels: they are also and frequently employed in an evaluative sense. However, unlike words like "good" or "bad", whose evaluative charge is stable even though they can be applied to very different things, in the case of "old" and "new" the affective load they carry depends on speaker, context, societal domain, and object. "Old" can be positively charged, for instance, when discussing antiques, or in professions or political or religious circles that value traditions and "old-fashioned reliability". In such cases it is equivalent to expressions such as "historic", "venerable", "(well) established", "tried", "tried-and-true". "Old" can be negatively charged when discussing technological equipment, or in youth culture, where it may connote "old-fashioned", "tired", "passé", and "obsolete". 22 "New" can be relatively neutral or negative, when used for "untried", "newfangled". It tends to convey positive affect in contexts in which it is equivalent to "fresh", "original", and "state-of-the-art". Different subgroups in society have different relationships to the new and the old in different domains. The flexibility of these terms makes it particularly easy for them to be weaponized for argumentative and rhetorical purposes.

In Greek and Latin, words for "new" are definitely not usually positively charged. Latin res novae (literally "new things") is a word for revolution, Greek kainotomia (from kainos "new") is the (senseless) pursuit of new things (for their own sake). On the other hand, even as early as the Odyssey we hear that people prefer to listen to the latest (neôtatê "newest", from neos, "new", "young") song. ${ }^{23}$ And the Athenians were in fact pretty radical innovators in many domains of life (D'Angour 2011; Sluiter 2018). However, even so there was ample scope for disagreement on the desirability of innovation. D'Angour (2011: 204) points out, for instance, how new musical styles gaining popularity in Athens in the 5th century BCE "were associated by conservative thinkers with educational laxness, sexual permissiveness and antisocial

\footnotetext{
${ }^{21}$ Ancient criticism of the practice is fairly rare (e.g. Cicero, Galen, see Sluiter 2015: 917).

${ }^{22}$ For "valuing the past" in classical antiquity, see Ker and Pieper (2014).

${ }^{23}$ Odyssey 1.351-352.
} 
individualism", terms of debate that may equally evoke the 1960 s of the last century. ${ }^{24}$ It is one of the contentions of the Anchoring Innovation program that these kinds of societal debates ultimately offer the frames and arguments for connecting what is new to what is familiar-in effect, "anchoring" the new.

But there is also a very concrete way to use the term "new" that in and of itself functions as an anchoring trope with relevant effects on the cognitive processing of a situation. This is the formula " $\mathrm{X}$ is the new $\mathrm{Y}$ ", a phrase to which several of the points raised earlier in this paper will turn out to be relevant, and which I will discuss at somewhat greater length to round off this paper. An unremarkable example-not the type of primary interest here-is a sentence such as "Das Gewicht der Worte is the new novel by Pascal Mercier". Here, there is a reference to a familiar category "novels by Pascal Mercier", with apparently a "new" item fitting that description. This is the type of "anchoring" the new by categorizing, labeling, and naming addressed by Bauer and Gaskell (1999) (Sect. 2).

A more striking use of the formula can be found in phrases such as the following:
a. Seaweed is the new kale. ${ }^{25}$
b. Why Team Resilience is the New Employee Engagement. ${ }^{26}$
c. Blockchain is hardly the "new internet". 27
d. Who is the new Mondrian? 28
e. This millennial may be the new Einstein. ${ }^{29}$
f. the new Homer. ${ }^{30}$
g. Hamberders is the new covfefe. ${ }^{31}$

\footnotetext{
${ }^{24} \mathrm{Cf}$. also the debate in Clouds by the comic poet Aristophanes between Right and Wrong, representatives of the older conservatives and the hip young respectively, where Wrong's strong point is claimed to be to think up new (kainas) thoughts. See D'Angour (2011: 214-215).

${ }^{25}$ Many instances on internet, e.g. https://www.mindbodygreen.com/0-25249/seaweed-is-the-newkale-a-doctor-explains.html, accessed Jan. 2019.

${ }^{26} \mathrm{https}: / / w w w . f o r b e s . c o m / s i t e s / k a r l y n b o r y s e n k o / 2018 / 12 / 27 /$ why-team-resilience-is-the-newemployee-engagement/, accessed Jan. 2019.

${ }^{27} \mathrm{https}: / /$ twitter.com/Xische/status/962597073248911360, accessed Jan. 2019.

${ }^{28} \mathrm{https}: / /$ tlmagazine.com/new-dutch-icons, Oct. 23, 2017, accessed Jan. 2019.

${ }^{29} \mathrm{https} / / / \mathrm{www}$. ozy.com/rising-stars/this-millennial-might-be-the-new-einstein/65094, about Sabrina Pasterski, accessed Jan. 2019.

${ }^{30}$ Raubitschek (1954).

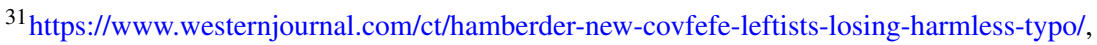
accessed Jan. 2019.
} 
In all these phrases ${ }^{32}$ we are again dealing with examples of categorical anchoring, but the anchor ("Y" in "X is the new $\mathrm{Y}$ ") is not a general category, but it is itself a prototype or best example of a category. The formula thus appeals to communal common ground (cf. Sect. 2), culturally shared information, either by the culture at large, or by a knowledgeable in-group. It is always relevant to establish what the relevant social group is, for which a piece of new information is anchored here. Example (a) is not that easy to process for people who are not into dieting and "superfoods": its successful understanding requires that we recognize "kale" as a prototype of the category "superfood", so that we realize the appropriate question to ask is not "what is the old kale, then?". "Kale" should immediately evoke its relevant category, so that we can successfully anchor "seaweed" into it. The same goes for example (b), "why team resilience is the new employee engagement", where the relevant social group should be one capable of processing "employee engagement" as a prototypical (or at least: recent) business strategy for optimizing team performance. Notice that "new" in both (a) and (b) is valued positively: the term announces that there is a new candidate for "best example" of a category. Both life-style advice and business counseling are domains in which new insights or pseudo-insights are put forward in rapid succession. They are sensitive to trends and fashions and there is very little resistance to change.

Example (c) belongs to a similarly rapidly developing area: information technology. I have added this example because it showcases the use of negation for purposes of managing common ground and expectations (Sect. 2). In "block chain is hardly the new internet", the negative adverb "hardly" contains an instruction on how to anchor the new "block chain" technology, through contradicting an expectation that was apparently in the common ground. Although block chain may be important and helpful, do not expect it to become as prototypically significant as the internet has been. The internet still holds its own. As an argumentative move, in all these examples a particular kind of starting point (what I would call the anchor) is evoked, which invites the audience to take a certain perspective, either through association or dissociation (van Eemeren 2019). The "basic critical question" that is raised is whether the implicit comparison is a valid one (van Eemeren 2019: 156; 161). ${ }^{33}$

Examples (d), (e), and (f) all have a cultural icon in the anchor-slot: Mondrian as the outstanding Dutch painter, Einstein as the brilliant scientist par excellence, and Homer as the canonical and unsurpassed poet. Both (d) and (e) announce that

\footnotetext{
${ }^{32}$ The existence of this formula was noted by Whitman (2004) (but others had spotted it before him, as he admits), who also coined the highly infelicitous term "snowclones" for it, inspired by Geoff Pullum of Language Log; see also Veszelszki (2017: 9-10 n. 4); Hill (2018: 426). The term is used pejoratively for a cliché, "lazy" expression. However, since I'm interested in its rhetorical, specifically its "anchoring" effects and its cognitive function, I will stick with the more neutral term "trope", or, as Hill calls it (1.c.) "ready-made template"; having a label does not mean the task of explaining how a linguistic feature works is done. I thank an anonymous referee for these references.

${ }^{33}$ Van Eemeren (2019) also suggests that the use of analogy argumentation is likely to belong to "the engaged", rather than to the "detached", style of argumentation, when "the still to be accepted state of affairs referred to in the standpoint is compared with an already familiar or easily recognizable state of affairs" (van Eemeren 2019: 167): I would call this an attempt at "anchoring".
} 
the search is on for a "new" candidate to fill the slot. Example (f) deserves a special comment: throughout Antiquity, candidates were identified (or offered themselves) for the predicate "the new Homer" (or "a second Homer", with slightly different framing). ${ }^{34}$ Mostly this was done without using the lexeme "new" (Lat. novus, Gr. neos, kainos). However, the trope $\mathrm{X}$ is the new $\mathrm{Y}$ was available even then: the virtually unknown C. Iulius Nicanor, a contemporary of the emperor Augustus, was known as the Neos Homeros, "new Homer" (see Raubitschek 1954). Nicanor may have written a Latin Iliad. Oddly, the man was also known as "the new Themistocles". Themistocles was the Greek general who had led the Athenians in the famous battle of Salamis, in which the Persians were defeated. Did Nicanor win a staged replication of this battle? Was he involved in financial dealings involving Salamis? We cannot be sure. However, what the example proves is that the trope was not a recent discovery and that it is more helpful to analyze its cognitive effects than simply to dismiss it as "laziness" or a "snowclone".

Finally, there is example (g), which within 10 years will most likely and hopefully be impossible to understand without explanatory commentary, to point at the relevance of "embedded cognition" for the successful processing of such sentences. Examples (a) and (b) are probably somewhat decipherable even in the future for people not belonging to the subcultures primarily addressed in them. However, the phrase "hamberders is the new covfefe" only makes sense in a very narrowly circumscribed historical setting. As elsewhere in $\mathrm{X}$ is the new $\mathrm{Y}$, "covfefe" forms the anchor and prototypically represents a category: that of the weird typos found with some regularities in tweets by President Donald Trump. "Covfefe" featured in an abortive tweet containing only the words "the constant negative press covfefe". 35 "Hamberders" (here quoted rather than used, as is clear from the singular predicate "is") was a spelling mistake for "hamburgers", the food offered by the President to a group of football players (see Sect. 2) when a government shutdown prevented more conventional White House dinner arrangements. The author of the quote notes with disapproval that people are "losing it" over a harmless typo when more urgent matters should be on their minds. In this case then, "new" does not imply approval of the substitution, but just registers it - though with some irritation at the addition of yet another irrelevant criticism. Without this context, it could have also been a gleeful criticism of the President's twitter habits.

A variant on the anchoring formula " $\mathrm{X}$ is the new $\mathrm{Y}$ ", is the form " $\mathrm{X}$ is the new thing".

h. Baby names inspired by health foods is the new thing. ${ }^{36}$

\footnotetext{
${ }^{34}$ E.g. Ennius is deemed Homerus alter, a second Homer, by the ancient satirist Lucilius (fragment 1189 ed. Marx $=$ fragment 413 ed. Warmington).

$35 @$ realDonaldTrump, 12:06 am, 31 May 2017, clearly meaning "coverage”. Lots of humorous suggestions on its meaning were made on Internet.

${ }^{36} \mathrm{https}$ ///www.wrmf.com/baby-names-inspired-by-health-foods-is-the-new-thing/, quoting names such as Kiwi (f.), Kale (m.), Maple (f.), and Clementine (f.). Accessed Jan. 2019.
} 
i. Ayurvedic eating is the new thing. ${ }^{37}$

j. LeBroning is the new thing all the kids are doing. ${ }^{38}$

k. Old is the new thing. ${ }^{39}$

Here, the background idea is specifically that people will be interested in learning what the latest fashion is-"the new thing". Once again, it is clear that particular domains of life lend themselves especially well to the accommodation of this phrase: mostly lifestyle issues, where "the new" is valued, even if it is represented, as in example (k) by "the old". Example (k) represents a situation in which both old and new are positively valued, if only because the old has unexpectedly become fashionable again. The accompanying text also demonstrates the extent to which "old" and "new" are a matter of social construction. The "old" is not "really" new: there is a renewed interest in it, and it is seen as a new asset class. Old is the new new, so to speak. A sentiment a classicist can only wholeheartedly approve of.

\section{Conclusion}

In this paper I have investigated the persuasive and argumentative uses of "anchoring" against the backdrop of its cognitive role in various domains of language, communication, and discourse. When taking "anchoring" as one's starting point and umbrella, a connection becomes apparent between different levels of linguistic communication. Seen through an "anchoring" lens, the linguistic and rhetorical phenomena here described connect ("associate", in Perelman and Olbrechts-Tyteca's (1969: 190) terms) something that is presented or constructed as new to something already deemed familiar. Discourse linguistic approaches suggest the importance of common ground management in directing the addressee to correctly anchor new information to knowledge that is mutually understood to be available, either on the basis of shared culture or of specific shared experiences of speaker and addressee. Categorizing, labeling and naming are ways to order and cognitively process new objects, ideas, practices and techniques, and connect or anchor them to what is familiar. Iconic features of language can be used to reinforce cognitive processing (Sect. 2).

I have also identified types of discursive practices that are particularly connected with anchoring: genealogy, mythology, aetiology, and etymology. All of these attempt to explain or justify a current situation by a narrative that anchors the status quo in a relevant point of origin in the past (genealogy, mythology, aetiology). This use

\footnotetext{
${ }^{37}$ https://www.smh.com.au/lifestyle/health-and-wellness/ayurvedic-eating-is-the-new-thing-hereis-how-to-do-it-20180815-p4zxmt.html, accessed Jan. 2019.

${ }^{38} \mathrm{https}$ ///deadspin.com/lebroning-is-the-new-thing-all-the-kids-are-doing-1501082101, accessed Jan. 2019. This refers to a propensity of famous basketballer LeBron James to drop to the floor in dramatic ways. The accompanying video shows kids imitating this behavior (and having it filmed).

${ }^{39}$ Blog 21 Aug. 2018, https://www.jlevines.com/2018/08/21/old-is-the-new-thing, accessed Jan. 2019: "the growing trend I've spotted in the design community is combining something old with something new ... also, there's a renewed interest in antique investing. And the thing is, it's seen as a "new", alternative, tangible asset class".
} 
of anchoring is particularly suitable in argumentative contexts and may belong to an "engaged" style of argumentation (cf. van Eemeren 2019: 166). In the case of the ancient practice of etymology (carefully to be distinguished from its modern scientific counterpart), anchoring takes place in a specific element of the common ground: language itself. The nouns (mostly nouns and names) that we use are cracked open as if they were containers to reveal information about the present (Sect. 3). Thus they are turned into epistemological and argumentative tools.

In Sect. 4 I turned to the lexemes of "old" and "new" themselves, and commented on their evaluative use. I then discussed a specific "anchoring trope": $X$ is the new $Y$, particularly those examples in which " $Y$ " represents a prototype of a category. Deciphering the phrase requires accessing communal common ground, whether "real" or constructed by the speaker, and sometimes of a kind only readily available to a specific sub-culture in society. The cognitive and rhetorical effect is again one of using analogical thinking to promote ease of processing and acceptability, in this case by evoking a familiar prototype of a category. ${ }^{40}$

\section{References}

Allan, R. J. (2017). Ancient Greek adversative particles in contrast. In C. Denizot \& O. Spevak (Eds.), Pragmatic approaches to Latin and Ancient Greek (pp. 273-301). Amsterdam-Philadelphia.

Allan, R. J., \& van Gils, L. (2015). Anchoring new ideas in common ground: A linguistic approach. Retrieved from http://www.academia.edu/24015356/Anchoring_new_ideas_in_com mon_ground._A_linguistic_approach.

Bauer, M. W., \& Gaskell, G. (1999). Towards a paradigm for research on social representations. Journal for the Theory of Social Behaviour, 29(2), 163-186.

Camp, E. (2018). Insinuation, common ground, and the conversational record. In D. Fogal, D. W. Harris \& M. Moss (Eds.), New work on speech acts (Chap. 2). Retrieved from http://www.oxford scholarship.com/view/10.1093/oso/9780198738831.001.0001/oso-9780198738831-chapter-2.

Clark, H. H. (1996). Using language. Cambridge: CUP.

Clark, H. H. (2016). Depiction as a method of communication. Psychological Review, 123, 324-347.

Clark, H. H., \& Brennan, S. (1991). Grounding in communication. In L. B. Resnick, J. M. Levine, \& S. D. Teasley (Eds.), Perspectives on socially shared cognition (pp. 127-149). Washington: APA Books.

D'Angour, A. (2011). The Greeks and the new: Novelty in ancient Greek imagination and experience. Cambridge: CUP.

Eco, U. (2000). Kant and the Platypus: Essays on language and cognition. Orlando: Harvest Books (A. McEwen, Trans.).

Goldwasser, O. (2017). What is a horse? Lexical acculturation and classification in Egyptian, Sumerian, and Nahuati. In T. Pommerening \& W. Bisang (Eds.), Classification from antiquity to modern times (pp. 45-64). Berlin-Boston: De Gruyter.

Hill, I. E. J. (2018). Memes, munitions, and collective copia: The durability of the perpetual peace weapons snowclone. Quarterly Journal of Speech, 104(4), 422-443.

Hofdstadter, D., \& Sander, E. (2013). Surfaces and essences: Analogy as the fuel and fire of thinking. New York: Basic Books.

\footnotetext{
${ }^{40} \mathrm{I}$ am grateful to the editors of this volume for their helpful comments, to the anonymous readers of this paper for their valuable suggestions, and to my colleagues in the Anchoring Innovation team, particularly Lidewij van Gils, Caroline Kroon and Luuk Huitink, for their comments and input.
} 
Huitink, L. (2009). Pragmatic presupposition and complementation in classical Greek. In S. J. Bakker \& G. C. Wakker (Eds.), Discourse cohesion in ancient Greek (pp. 21-40). Leiden: Brill (Amsterdam Studies in Classical Philology 16).

Ker, J., \& Pieper, C. (Eds.). (2014). Valuing the past in the Greco-Roman world. Leiden: Brill.

Klooster, J. J. H., \& Wessels, A. B. (Eds.). (forthcoming). Inventing Origins: The Function of Aetiology in Antiquity.

Kroon, C. M. J. (2015). 'Anchoring' as a communicative device in Roman historiography: A discourse linguistic perspective. Retrieved from http://www.academia.edu/24059119/Anchor ing_as_a_communicative_device_in_Roman_historiography_a_discourse_linguistic_perspec tive.

Kroon, C. M. J. (2017). Textual deixis and the 'anchoring' use of the Latin pronoun hic. Mnemosyne, $70,585-612$.

Kroon, C. M. J. (2019). Communicative anchoring in Latin: Devices and strategies for common ground management [unpublished keynote at 20th ICLL, Las Palmas, 18 June 2019].

Loraux, N. (2006). The invention of Athens. The funeral oration in the classical city. New York: Zone Books (Transl. from the French 1981 original by Alan Sheridan; L' invention d' Athènes: Histoire de l'oraison funèbre dans la 'cité classique'. Paris: Mouton).

Moscovici, S. (1976). La psychanalyse, son image et son public. Paris: PUF (2nd rev. edition, first ed. 1961).

Nijk, A. A. (2018). Iconiciteit als taalkundig anker. Lampas, 51, 312-325.

Perelman, C., \& Olbrechts-Tyteca, L. (1969). The new rhetoric: Treatise on argumentation. Notre Dame-London: University of Notre Dame Press [Engl. tr. of Perelman, C., \& Olbrechts-Tyteca, L. (1958). Traité de l'argumentation. Paris: Presses Universitaires de France.].

Perry, J. M., \& Jamison, S. (1997). In the zone. Achieving optimal performance in business-As in sports. Chicago: Contemporary Books.

Raubitschek, A. E. (1954). The new homer. Hesperia: The Journal of the American School of Classical Studies at Athens, 23, 317-319.

Rotstein, A. (2016). Literary history in the Parian Marble. Washington DC: Center for Hellenic Studies. Retrieved from https://chs.harvard.edu/CHS/article/display/6492.andrea-rot stein-literary-history-in-the-parian-marble.

Sluiter, I. (1990). Ancient grammar in context: Contributions to the study of ancient linguistic thought. Amsterdam: VU University Press.

Sluiter, I. (2015). Ancient etymology: A tool for thinking. In F. Montanari, S. Matthaios, \& A. Rengakos (Eds.), Brill's companion to ancient Greek scholarship (pp. 896-922). Leiden: Brill.

Sluiter, I. (2017). Anchoring innovation: A classical research agenda, European Review, 25(1), 20-38. Retrieved from https://www.cambridge.org/core/journals/european-review/article/divclasstitleanchoring-innovation-a-classical-research-agendadiv/EB4A06F32AA42EAE8F732 DF658687A42.

Sluiter, I. (2018). Oud is het nieuwe nieuw: Een inleiding op anchoring innovation. Lampas, 51, 289-295.

Stalnaker, R. (2002). Common ground. Linguistics and Philosophy, 25, 701-721.

van Eemeren, F. H. (2019). Argumentative style: A complex notion. Argumentation, 33, 153-171.

van Gils, L. (2016). Common ground in Latin discourse: Two case studies of narrative negation in Cicero and Vergil. In P. Pocetti (Ed.), Latinitatis rationes: Descriptive and historical accounts for the Latin language (pp. 763-779). Berlin-Boston: De Gruyter.

Veszelszki, Á. (2017). Digilect: The impact of infocommunication technology on language. BerlinBoston: De Gruyter.

Whitman, G. (2004). Phrases for lazy writers in kit form are the new clichés. Retrieved from ago raphilia.blogspot.com/2004/01/phrases-for-lazy-writers-in-kit-form.html. 
Ineke Sluiter is Professor of Greek at Leiden University. Her research focuses on ancient ideas on language (grammar, rhetoric, literary interpretation), and the use of value discourse in societal debates in Antiquity. She is the recipient of a 2010 Spinoza Award, and the PI of the research program 'Anchoring Innovation'.

Open Access This chapter is licensed under the terms of the Creative Commons Attribution 4.0 International License (http://creativecommons.org/licenses/by/4.0/), which permits use, sharing, adaptation, distribution and reproduction in any medium or format, as long as you give appropriate credit to the original author(s) and the source, provide a link to the Creative Commons license and indicate if changes were made.

The images or other third party material in this chapter are included in the chapter's Creative Commons license, unless indicated otherwise in a credit line to the material. If the material is not included in the chapter's Creative Commons license and your intended use is not permitted by statutory regulation or exceeds the permitted use, you will need to obtain permission directly from the copyright holder. 